\title{
ISOLATION OF SPECIES OF YERSINIA FROM PATIENTS WITH GASTROENTERITIS IN NIGERIA
}

\author{
D. E. Agbonlahor, T. O. Odugbemi and O. Dosunmu-Ogunbi
}

Department of Microbiology and Parasitology, College of Medicine, University of Lagos, PMB 12003, Lagos, Nigeria

\begin{abstract}
Summary. From patients in Nigeria with acute gastroenteritis, strains of Yersinia were isolated from $14(1.3 \%)$ of 1082 specimens of faeces examined specifically for yersiniae by direct plating and after cold enrichment. Clinical significance was ascribed to six isolates of $Y$. enterocolitica (serotypes O3, O5,27 and 09 ) but not to seven isolates of $Y$. intermedia or one isolate of $Y$. frederikseni.
\end{abstract}

\section{INTRODUCTION}

There continues to be a world-wide increase in the number of reports of infection with Yersinia enterocolitica in man. The most common clinical presentation is gastrointestinal disturbance, with isolates of serogroups $\mathrm{O} 3, \mathrm{O} 5,27, \mathrm{O} 8$ and $\mathrm{O} 9$ most frequently implicated.

Rhamnose-fermenting $\left(\mathrm{Rha}^{+}\right)$and other biochemically atypical strains, previously called $Y$. enterocolitica-like, are usually isolated from environmental sources including water, milk and foods or from animals (Lassen, 1972; Brenner et al., 1976; Chester et al., 1977; Kapperud, 1977; Schiemann and Toma, 1978). Recent studies of biochemical characteristics and DNA-relatedness have indicated, however, the existence of at least four species: $Y$. enterocolitica sensu stricto (Bercovier et al., 1980a); Y. frederikseni-rhamnose-positive $\left(\mathrm{Rha}^{+}\right)$strains (Ursing et al., 1980); $Y$. intermedia-rhamnose-, melibiose- and raffinose-positive $\left(\mathrm{Rha}^{+}, \mathrm{Mel}^{+}, \mathrm{Raf}^{+}\right)$strains (Brenner et al., 1980); and Y. kristenseni-sucrose-negative (Suc ${ }^{-}$) strains (Bercovier et al., $1980 b$ ).

Many of the reports of the isolation of yersiniae from man have come from laboratories in which these organisms were sought specifically. In other countries in which detailed studies have not been made, little is known of the distribution of yersiniae in man and the environment. For example, there are only two short reports of the isolation of $Y$. enterocolitica (one strain) or $Y$. enterocolitica-like organisms (two strains) from patients with gastroenteritis in Nigeria (Anjorin et al., 1979; Agbonlahor, Odugbemi and Lasi, 1981). The aims of the present study, therefore, were to determine the prevalence and assess the clinical significance of Yersinia species isolated from patients with gastrointestinal disturbances in Nigeria.

\section{MATERIALS AND METHODS}

Antisera. Diagnostic antisera against $\mathrm{O}$ determinants $\mathrm{O} 1, \mathrm{O} 2 \mathrm{a}, \mathrm{O} 2 \mathrm{~b}, \mathrm{O} 3, \mathrm{O} 5, \mathrm{O} 5,27, \mathrm{O} 8$ and $\mathrm{O} 9$ of $Y$. enterocolitica were kindly donated by Professor G. Wauters, Cliniques Universitaires St Luc, Brussels, and Professor S. Winblad, Institute of Clinical Bacteriology, Malmo, Sweden.

The survey. A total of 1082 specimens of faeces from patients with acute gastroenteritis was examined specifically for $Y$. enterocolitica at the Lagos University Teaching Hospital. Faeces were spread on plates of MacConkey Agar (Oxoid) and Salmonella-Shigella Agar (Oxoid) that were incubated at $23^{\circ} \mathrm{C}$ for $48 \mathrm{~h}$. For cold enrichment, a loopful of faeces was inoculated into

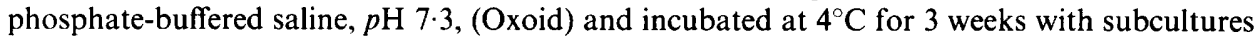
made at 2, 7, 14 and 21 days on to plates of MacConkey Agar and Salmonella-Shigella Agar that were incubated at $23^{\circ} \mathrm{C}$ for $48 \mathrm{~h}$. Lactose non-fermenting colonies present on any selective agar 
were tested for their reaction with Gram's stain, urease and phenylalanine deaminase activities, nitrate reduction and motility at $23^{\circ} \mathrm{C}$ and $37^{\circ} \mathrm{C}$. The identity of cultures behaving biochemically like Yersinia was confirmed and they were assigned to species by their reactions in tests for fermentation of melibiose, raffinose, rhamnose and sucrose and for citrate utilisation (Bercovier et al., 1980a). Isolates of $Y$. enterocolitica were serotyped.

Antimicrobial susceptibility tests were performed by standard techniques with the Multodisk No. 7402E (Oxoid) containing the following antimicrobial agents: ampicillin ( $2 \mu \mathrm{g})$; cephaloridine $(5 \mu \mathrm{g})$; chloramphenicol $(10 \mu \mathrm{g})$; gentamicin $(10 \mu \mathrm{g})$; streptomycin $(10 \mu \mathrm{g})$; sulphafurazole $(100 \mu \mathrm{g})$; sulphatriad $(300 \mu \mathrm{g})$; and tetracycline $(10 \mu \mathrm{g})$. Susceptibilities of cultures were also tested with individual disks containing amoxycillin $(20 \mu \mathrm{g})$ and augmentin $(30 \mu \mathrm{g}$; i.e., amoxycillin $20 \mu \mathrm{g}$ and clavulanic acid $10 \mu \mathrm{g}$ ) kindly donated by Beecham Research Laboratories, Great West Road, Brentford, Middlesex TW8 9BD. The inoculum was a 1000-fold dilution of an 18-h culture of the test strain grown in Mueller-Hinton Broth (Oxoid) at $23^{\circ} \mathrm{C}$. The zones of inhibition obtained with each strain with different antibiotics were compared with those given by a culture of Escherichia coli strain NCTC10418.

$\beta$-Lactamase activity was assessed by a starch paper technique (Odugbemi, Hafiz and McEntegart, 1977).

Clinical evaluation. We followed essentially the recommended criteria of Bottone (1978). Thus, the recovery on primary plating of a Yersinia strain from the faeces of patients with bloody or non-bloody diarrhoea, with either or both of abdominal pain and fever, in the absence of parasites or other bacterial pathogens such as Salmonella, Shigella or Vibrio species and enteropathogenic serotypes of $E$. coli, was considered clinically significant; viruses and Campylobacter species were not sought. The sera of patients were not tested for antibodies to Yersinia.

\section{RESULTS AND DISCUSSION}

\section{Characters of Yersinia isolates}

Yersinia species were isolated from only 14 of 1082 specimens of faeces examined in this survey. All 14 isolates gave positive results in tests for urease production, nitrate reduction and motility at $23^{\circ} \mathrm{C}$ and negative results in tests for motility at $37^{\circ} \mathrm{C}$ and phenylalanine deaminase production. In extensive tests with a wide range of substrates (unpublished data) the observed biochemical reactions suggested that each isolate behaved like $Y$. enterocolitica or was $Y$. enterocolitica-like (Bercovier et al., 1980a). Six of the 14 isolates did not ferment rhamnose,

TABLE

Isolation of Yersinia species from patients with gastroenteritis in Nigeria

\begin{tabular}{|c|c|c|c|c|c|c|}
\hline $\begin{array}{l}\text { Patient } \\
\text { no. }\end{array}$ & Sex & $\begin{array}{c}\text { Age } \\
\text { (years) }\end{array}$ & $\begin{array}{l}\text { Yersinia sp. } \\
\text { isolated }\end{array}$ & $\begin{array}{l}\text { Isolation } \\
\text { method }\end{array}$ & Serotype & $\begin{array}{l}\text { Other pathogenic } \\
\text { species isolated }\end{array}$ \\
\hline 1 & $\mathrm{~F}$ & 16 & Y. enterocolitica & DP & $\mathrm{O} 3$ & none \\
\hline 2 & $\mathrm{~F}$ & 30 & $Y$. enterocolitica & DP & $\mathrm{O} 3$ & none \\
\hline 3 & $\mathrm{M}$ & 1.5 & $Y$. enterocolitica & DP & O3 & none \\
\hline 4 & $\mathrm{M}$ & 10 & $Y$. enterocolitica & DP & O3 & none \\
\hline 5 & $\mathrm{~F}$ & $<1$ & $Y$. enterocolitica & DP & 05,27 & none \\
\hline 6 & $\mathrm{M}$ & 58 & $Y$. enterocolitica & $\mathrm{CE}$ & O9 & none \\
\hline 7 & $\mathrm{~F}$ & $<1$ & $Y$. intermedia & $\mathrm{CE}$ & NT & Entamoeba histolytica \\
\hline 8 & $\mathrm{~F}$ & 26 & $Y$. intermedia & $\mathrm{CE}$ & NT & E. histolytica \\
\hline 9 & $\mathrm{~F}$ & 34 & $Y$. intermedia & DP & NT & none \\
\hline 10 & $\mathrm{M}$ & $2 \cdot 5$ & $Y$. intermedia & $\mathrm{CE}$ & NT & ETEC \\
\hline 11 & $\mathrm{M}$ & 3 & $Y$. intermedia & $\mathrm{CE}$ & NT & Giardia intestinalis \\
\hline 12 & $\mathrm{M}$ & 4 & $Y$. intermedia & $\mathrm{CE}$ & NT & ETEC \\
\hline 13 & $\mathrm{M}$ & 33 & $Y$. intermedia & $\mathrm{CE}$ & NT & Trichuris trichiura \\
\hline 14 & M & $<1$ & Y. frederikseni & $\mathrm{CE}$ & NT & G. intestinalis \\
\hline
\end{tabular}

$\mathrm{DP}=$ direct plating; $\mathrm{CE}=$ cold enrichment; $\mathrm{NT}=$ not serotypable with available antisera (see Methods); ETEC = serotypes of enterotoxigenic Escherichia coli. 
melibiose or raffinose and did not utilise citrate and, hence, behaved like strains of $Y$. enterocolitica sensu stricto; these isolates were of $\mathrm{O}$ serotypes common in human infection (table). The other eight isolates fermented rhamnose $\left(\mathrm{Rha}^{+}\right)$; none was serotypable with the available $Y$. enterocolitica $\mathrm{O}$ antisera. Seven of the eight $\mathrm{Rha}^{+}$isolates also fermented melibiose and raffinose and utilised citrate and were, therefore, probably strains of $Y$. intermedia (Brenner et al., 1980). The remaining $\mathrm{Rha}^{+}$isolate was $\mathrm{Mel}^{-}, \mathrm{Raf}^{-}$and did not utilise citrate; it appeared to be a strain of $Y$. frederikseni (Ursing et al., 1980).

Each of the 14 isolates produced $\beta$-lactamase and was resistant to ampicillin, amoxycillin and cephaloridine but sensitive to augmentin. Most of the 14 isolates were also sensitive to chloramphenicol, gentamicin, streptomycin, sulphafurazole, sulphatriad and tetracycline.

\section{Clinical significance}

Five of the six cultures of $Y$. enterocolitica were of serotypes $\mathrm{O} 3$ or O5,27 and were isolated in significant numbers on primary plating independently of other intestinal pathogens (table); thus, these isolates were the probable causative agents of the gastrointestinal infections in patients 1 to 5. From patient 6 , an isolate of $Y$. enterocolitica of serotype $\mathrm{O} 9$ was obtained, but only after cold enrichment, and it is difficult to ascribe to that isolate a definitive role in the patient's illness. However, in view of the recurrent nature of the illness in that patient, prolonged carriage of the strain cannot be excluded, and it is generally agreed that cold enrichment is desirable for the isolation of $Y$. enterocolitica from carriers who may excrete few organisms (van Noyen et al., 1981).

On the other hand, isolation of $Y$. intermedia and $Y$. frederikseni from the faeces of seven patients was made only after cold enrichment, and other intestinal pathogens were present which might have accounted for their illness (table). Thus, the association between these Yersinia isolates and the gastrointestinal illnesses of these seven patients would seem doubtful (van Noyen et al., 1981). The strain of $Y$. intermedia from patient 9, however, was isolated after direct plating of the faeces. Although it might be tempting to ascribe a pathogenic role to it on the basis of its presence in significant numbers in the faeces of that patient, it must be noted that the presence of other potential pathogens such as viruses and Campylobacter species was not excluded.

Further work, including studies of healthy populations, will be required to increase our understanding of the distribution, epidemiology and pathogenicity of species of Yersinia in Nigeria and other countries.

We are indebted to Professor G. Wauters and Professor S. Winblad for the gift of Yersinia antisera used in this study. An In-service Award to one of us (DEA) from the Director of the National Veterinary Research Institute, Vom, Nigeria, is gratefully acknowledged.

\section{REFERENCES}

AgBONLAhOR, D. E., OdUGBemi, T. O. AND LASI, Q. 1981. Isolation of Yersinia enterocolitica from stools of acute gastroenteritis cases in Lagos, Nigeria. East African Medical Journal, 58, 520-524.

Anjorin, F. I., Sturrock, R. D., Subbuswamy, S. G., Lawande, R. V. and Fakunle, Y. M. 1979. Yersinia enterocolitica infection from West Africa-a case report. Transactions of the Royal Society of Tropical Medicine and Hygiene 73, 634-635.

Bercovier, H., Brenner, D. J., Ursing, J., Steigerwalt, A. G., Fanning, G. R., Alonso, J. M., Carter, G. P., AND Mollaret, H. H. 1980a. Characterization of Yersinia enterocolitica sensu stricto. Current Microbiology, 4, 201-206.

Bercovier, H., Ursing, J., Brenner, D. J., Steigerwalt, A. G., Fanning, G. R., Carter, G. P., AND Mollaret, H. H. 1980b. Yersinia kristensenii: A new species of Enterobacteriaceae composed of sucrose-negative strains (formerly called atypical Yersinia enterocolitica or Yersinia enterocolitica-like). Current Microbiology, 4, 219-224.

BotTone, E. J. 1978. Atypical Yersinia enterocolitica: Clinical and epidemiological parameters. Journal of Clinical Microbiology, 7, 562-567.

Brenner, D. J., Bercovier, H., Ursing, J., Alonso, J. M., Steigerwalt, A. G., Fanning, G. 
R., Carter, G. P. and Mollaret, H. H. 1980. Yersinia intermedia: A new species of Enterobacteriaceae composed of rhamnose-positive, melibiose-positive, raffinose-positive strains (formerly called atypical Yersinia enterocolitica or Yersinia enterocolitica-like). Current Microbiology, 4, 207-212.

Brenner, D. J., Steigerwalt, A. G., Falcao, D. P., Weaver, R. E. and Fanning, G. R. 1976. Characterization of Yersinia enterocolitica and Yersinia pseudotuberculosis by deoxyribonucleic acid hybridization and by biochemical reactions. International Journal of Systematic Bacteriology, 26, 180-194.

Chester, B., Stotzky, G., Bottone, E. J., Malowany, M. S. and Allerhand, J. 1977. Yersinia enterocolitica: biochemical, serological and gas-liquid chromatographic characterization of rhamnose-, raffinose-, melibiose-, and citrate-utilizing strains. Journal of Clinical Microbiology, 6, 461-468.

KAPPERUD, G. 1977. Yersinia enterocolitica and Yersinia-like microbes isolated from mammals and water in Norway and Denmark. Acta Pathologica et Microbiologica Scandinavica, 85B, 129-135.

LASSEN, J. 1972. Yersinia enterocolitica in drinking water. Scandinavian Journal of Infectious Diseases, 4, 125-127.

Odugbemi, T. O., Hafiz, S. and McEntegart, M. G. 1977. Penicillinase-producing Neisseria gonorrhoeae: detection by starch paper technique. British Medical Journal, 2, 500.

SchiemanN, D. A. AND Toma, S. 1978. Isolation of Yersinia enterocolitica from raw milk. Applied and Environmental Microbiology, 35, 54-58.

Ursing, J., Brenner, D. J., Bercovier, H., Fanning, G. R., Steigerwalt, A. G., Brault, J. AND Mollaret, H. H. 1980. Yersinia frederiksenii: A new species of Enterobacteriaceae composed of rhamnose-positive strains (formerly called atypical Yersinia enterocolitica or Yersinia enterocolitica-like). Current Microbiology, 4, 213-217.

VAN Noyen, R., Vandepitte, J., Wauters, G. and Selderslaghs, R. 1981. Yersinia enterocolitica: its isolation by cold enrichment from patients and healthy subjects. Journal of Clinical Pathology, 34, 1052-1056. 